\title{
INJIL DAN ISLAM ABANGAN JAWA: SUATU
}

\section{PENDEKATAN KONTEKSTUAL}

SOERONO

\section{PENDAHULUAN}

"Whither Muslim evangelism in the 2000's?"4 demikian pertanyaan kepedulian dari Phil Parshall. Menurut Parshall, tidak seperti tahun 1980an ketika hal menjadi misionaris di negara Islam menjadi suatu tren dan kebanggaan, tahun 2000-an diwarnai kendurnya misi ke dunia Islam. Sungguh patut disayangkan padahal Islam merupakan agama yang paling cepat pertumbuhannya di dunia ini.5

Bagaimanapun juga, dunia Islam yang luas tidak boleh dipahami sebagai dunia yang "monolithic."6 Sama seperti dalam kekristenan yang sangat majemuk, demikian juga Islam. Salah satu blok besar (kira-kira 70 \%)7 yang membentuk dunia Islam adalah apa yang disebut, "Islam Abangan," (Inggris, "Folk Islam" atau "Popular Islam"). Islam golongan ini bersifat sinkretistik, utamanya diwarnai dengan pandangan dunia yang animistik. Di Indonesia, Islam Abangan Jawa adalah representasi yang sangat tepat dari Islam golongan ini. Makalah ini akan berusaha untuk pertama-tama meletakkan dasar alkitabiah bagi praktik kontekstualisasi secara singkat, kemudian disusul dengan pemahaman pandangan dunia Islam Jawa dan terakhir ditutup dengan usaha untuk menemukan "theological bridge" demi menjangkau kelompok Islam Jawa tersebut secara efektif.

\footnotetext{
4 Phil Parshall, "Missiological Issues for the New Millenium," dalam The Last Great Frontier: Essays on Muslim Evangelism (Quezon City: Open Doors with Brother Andrew, 2000) 27.

5 Parshall memandang pertumbuhan tersebut dari dua sudut pandang. Pertama, itu disebabkan karena pertumbuhan biologis sebab Islam menolak segala bentuk alat kontrasepsi. Kedua, melalui penyebaran agama Islam seperti yang terjadi di Afrika. Ibid, 28.

6 Phil Parshall, Bridges to Islam: A Christian Perspective on Folk Islam (Grand Rapids: Baker, 1983) 16.

7 Ibid.
} 


\section{PEMBERITAAN INJIL DAN KONTEKSTUALISASI}

Yesus berkata kepada para murid-Nya, "Pergilah ke seluruh dunia, beritakanlah Injil kepada segala makhluk" (Mrk. 16:15). Dua kata dalam ayat ini layak diperhatikan: "seluruh" dan "segala." Ke dua kata tersebut tidak lain menegaskan bahwa Injil bersifat universal-bagi semua. Injilnya satu namun penerimanya semua-tidak terbatas. Di sinilah letak tantangan untuk berkontekstualisasi. Bagaimanapun, sebelum tantangan tersebut menjadi tantangan bagi gereja, maka itu menjadi tantangan bagi Allah. Injil yang diperuntukkan bagi semua, pertama-tama harus Allah kontekstualisasikan dalam konteks budaya tertentu agar berita baik itu dapat diterima oleh penerima mula-mula. Itulah sebabnya tidak heran jika kita menemukan Alkitab sendiri adalah produk kontekstualisasi-Allah berbicara melalui bahasa manusia. 8

Gereja pada gilirannya melanjutkan semangat Allah untuk mengupayakan pemberitaan Injil yang relevan dalam konteks masyarakat tertentu. Jadi, kontekstualisasi lahir dari asumsi bahwa konteks yang berbeda membutuhkan pendekatan yang berbeda pula.9 Jika demikian, maka ada dua tuntutan dalam kontekstualisasi. Pertama, Injil yang diberitakan secara substansial harus berpadan dengan berita Injil yang bersumber langsung dari Allah. Kedua, Injil harus disampaikan dengan memperhatikan budaya masyarakat penerima. Sehingga tepat sekali jika kita mendefinisikan kontekstualisasi sebagai: "Meaningful and appropriateness cross-cultural transmission of biblical truth which is faithful to its original intent and sensitive to culture."10

\footnotetext{
8 Allah bukan hanya pencetus konsep kontekstualisasi namun Ia adalah pelaku kontekstualisasi par exellence melalui inkarnasi Anak-Nya. Seperti yang dinyatakan dalam Willowbank Report on the Gospel and Culture bahwa inkarnasi adalah "... most spectacular instance of cultural identification in the history of mankind, since by his incarnation the Son became a first-century Galilean Jew." Seperti yang dikutip Rick Love dalam Muslims, Magic and the Kingdom of God (Pasadena: William Carey, 2000) 11.

9 Jadi prosedurnya, karena Allah telah mengkontekstualisasikan berita-Nya dalam budaya tertentu, maka kita harus mulai dengan dekontekstualisasi baru kemudian rekontekstualisasi.

10 Dikutip dari "S I M Guidelines for Muslim Ministry," dalam Parshall, Great Frontier, 46. Kontekstualisasi model ini, seperti yang dipraktikan oleh David J. Hesselgrave, dengan tepat digambarkan oleh Stephen B. Bevans sebagai model Translation. Model ini adalah model yang paling dekat dengan jantung teologi Injili. Namun demikian, Bevans sendiri keberatan dengan model ini karena tidak ada apa yang ia sebut dengan 'naked
} 
Inilah yang diperjuangkan Paulus dalam pelayanannya sebagai pemberita Injil. 1 Korintus 9:19-23 melukiskan hal ini dengan sangat baik. Ia menulis:

Sungguhpun aku bebas terhadap semua orang, aku menjadikan diriku hamba dari semua orang, supaya aku boleh memenangkan sebanyak mungkin orang. Demikianlah bagi orang Yahudi aku menjadi seperti orang Yahudi, supaya aku memenangkan orangorang Yahudi. Bagi orang-orang yang hidup di bawah hukum Taurat aku menjadi seperti orang yang hidup di bawah hukum Taurat, sekalipun aku sendiri tidak hidup di bawah hukum Taurat, supaya aku dapat memenangkan mereka yang hidup di bawah hukum Taurat. Bagi orang-orang yang tidak hidup di bawah hukum Taurat aku menjadi seperti orang yang tidak hidup di bawah hukum Taurat, sekalipun aku tidak hidup di luar hukum Allah, karena aku hidup di bawah hukum Kristus, supaya aku dapat memenangkan mereka yang tidak hidup di bawah hukum Taurat. Bagi orang-orang yang lemah aku menjadi seperti orang yang lemah, supaya aku dapat menyelamatkan mereka yang lemah. Bagi semua orang aku telah menjadi segala-galanya, supaya aku sedapat mungkin memenangkan beberapa orang dari antara mereka. Segala sesuatu ini aku lakukan karena Injil, supaya aku mendapat bagian dalamnya.

Bagian ini tidak hanya menggambarkan pengorbanan Paulus yang luar biasa bagi pekerjaan pemberitaan Injil (dari orang "bebas" menjadi "hamba dari semua orang”), namun juga bagaimana Paulus mengkomunikasikan Injil kepada berbagai kelompok orang. Kepada orang (konteks) yang berbeda, Paulus menggunakan pendekatan yang berbeda pula. Dalam bagian ini, frasa "menjadi seperti" (muncul lima kali) mewakili pendekatan kontekstual Paulus dalam pemberitaan Injilnya. Apakah ini berarti Paulus telah mengorbankan substansi Injil demi relevansi? Rick Love dengan tepat menggaris-bawahi frasa "hidup di bawah hukum Kristus" sebagai batasan atau "parameter" dalam berkontekstualisasi. Ini berarti bahwa kontekstualisasi a la Paulus selalu dikerjakan di dalam koridor teologis dan etis hukum Kristus. 11 Peka terhadap konteks tidak berarti membuka pintu

gospel' (berita Kristen yang suprakultural). Alasan Bevans adalah hampir tidak mungkin mengupas tuntas kulit budaya dari Injil. Pertanyaannya adalah: Jika kita tidak mungkin melakukannya bagaimana kita bisa mengetahui keunikan Injil itu sendiri? Bagaimana kita bisa memastikan bahwa Injil itu sendiri berasal dari Allah dan bukan produk budaya? Jika tidak mungkin memisahkan Injil dari kemasan budaya maka sesungguhnya Injil bukan Injil. Lihat Stephen B. Bevans, Models of Contextual Theology (New York: Orbis Books, 1999) 36-37.

11 Love, 54-55. 
terhadap sinkretisme, sebaliknya kontekstualisasi adalah mengkomunikasikan Injil Kristus dalam kerangka hukum Kristus. Dengan demikian, sekalipun istilah "kontekstualisasi" sendiri menegaskan konteks itu penting, namun konteks tetap harus tunduk kepada otoritas teks (Alkitab).

\section{SEKILAS WAJAH ISLAM JAWA}

Berbagai sumber untuk merekonstruksi sejarah awal perkembangan Islam di Jawa tampaknya memberikan penanggalan yang berbeda tentang kapan masuknya Islam ke Jawa. Menurut Damais, Islam sudah eksis di Jawa sejak akhir abad 14 T. M., sementara yang lain memberikan penanggalan dalam kisaran abad 15-16 T. M.12 Harus diakui bahwa perkembangan agama Islam di Jawa itu bersifat bertahap. Awalnya para pedagang dari India yang pertama membawa Islam masuk ke Jawa, namun para sufi, ulama dan raja Muslimlah yang memberikan sumbangan terbesar dalam perkembangannya.13 Raja-raja inilah yang paling berperan sebab, seperti yang dikatakan Woodward,

Sejarah Islam Jawa tidak sekadar soal konversi saja, tapi juga soal penegaran Islam sebagai agama kerajaan, suatu proses yang menyebabkan penghancuran banyak kebudayaan Hindu-Budha yang ada dan sub-ordinasi ulama atas kekuasaan keraton.14

Sejarah perkembangan awal Islam di Jawa barangkali tidak semenarik bagaimana Islam berinteraksi dengan budaya lokal dan kepercayaankepercayaan pra-Islam. Sebutan "Islam Jawa" (gabungan antara Islam dan kejawen) sendiri sudah mengundang pertanyaan sejauh mana keduanya saling mempengaruhi. Apa menaklukkan apa? Atau mana yang lebih kuat

12 Sumber-sumber yang dipakai untuk menjadi dasar penanggalan itu mencakup: sumber tradisional (abad $15 \mathrm{~T}$. M.), sumber China (awal abad 15 T. M.), Inskripsi Hindu-Jawa (akhir abad 15 T. M.) dan sumber Portugis (awal abad 16 T. M.). Woodward sendiri mengaku karena tidak adanya sumber yang cukup, maka kita tidak mungkin dogmatis dalam hal ini. Lihat Mark R. Woodward, Islam Jawa: Kesalehan Normatif Versus Kebatinan (Yogyakarta: LKiS, 1999) 80.

13 Ibid.

14 Ibid. 
pengaruhnya? Pertanyaan-pertanyaan semacam ini, menurut Sumanto Al Qurtuby, adalah pola pikir “menang-kalah” yang harus ditinggalkan. Sejalan dengan Akbar S. Ahmad dan Ulil, Al Qurtuby mengajak kita untuk melihat Islam Jawa sebagai “ekspresi Islam setelah bertemu dengan unsurunsur lokal."15 Dengan demikian, gagasan dominasi atau penundukan sekarang diganti dengan “dialog.”16 Di sinilah Al Qurtuby melihat sinkretisme sebagai sesuatu yang tak terelakkan. "Tidak ada agama apa pun di dunia ini yang tidak 'sinkretistik,"'17 katanya. Berangkat dari sini, jika kita berbicara tentang Islam Jawa maka kita sedang berbicara tentang perpaduan antara Islam dan kejawen. Bahkan Wali Sanga, yang memiliki andil besar dalam penyebaran Islam di Jawa, tidak memperkenalkan Islam eksklusif; sebaliknya, mereka menawarkan Islam kompromis-memberi cukup ruang bagi kepercayaan-kepercayaan lokal yang bersifat takhyul dan animistik. 18

Pada bagian pendahuluan sudah disinggung bahwa Islam tidak boleh dipandang sebagai dunia yang homogen. Ini tidak hanya berlaku dalam skup global namun juga dalam konteks khusus. Islam Jawa, misalnya, memiliki varian-varian berkenaan dengan kepercayaan dan praktik keagamaan mereka. Clifford Geertz, dalam karya klasiknya The Religion of Java, mengklasifikasikan varian-varian tersebut ke dalam tiga bagian besar: priayi, santri dan abangan.19 Menurutnya, kelompok priyayi adalah kelompok elit kerah-putih yang biasanya duduk di pemerintahan. Dalam hal kepercayaan, kelompok ini mewarisi kepercayaan-kepercayaan HinduJawa. Sementara kelompok Santri (ortodoks) lebih menekankan pada aspek-aspek keislaman dan umumnya mereka berhubungan dengan dunia perdagangan, namun juga pertanian. Mereka adalah penganut Islam

15 Sumanto Al Qurtuby, "Sinkretisme dalam 'Islam Jawa," WASKITA: Jurnal Studi Agama dan Masyarakat Vol. I, no. 1 (April 2004): 73.

16 Ibid, 74. Azyumardi Azra lebih suka menggunakan istilah "adhesi." Dalam konteks penyebaran Islam secara umum di kepulauan Melayu-Indonesia, Ia mengatakan bahwa penyebaran Islam lebih tepat dipahami sebagai "adhesi" daripada "konversi." Itu berarti bahwa Islam diterima oleh penduduk nusantara tanpa meninggalkan kepercayaan dan praktik keagamaan yang lama. Lihat Azyumardi Azra, Islam Nusantara: Jaringan Global dan Lokal (Bandung: Mizan, 2002) 20.

17 Ibid, 75.

18 Lihat M. Murthado, Islam Jawa: Keluar dari Santri Vs Abangan (Yogyakarta: Lappera Pustaka Utama, 2002) 23.

19 Clifford Geertz, The Religion of Java (Illinois: The Free Press, 1960) 6. 
normatif atau meminjam istilah Woodward "kesalehan normatif" yang berpusat pada syariah.20 Akhirnya, kelompok Abangan (heterodoks), masyarakat pertanian atau pedesaan, yang mana kepercayaan mereka diwarnai dengan pandangan dunia yang animistik.21 Sekalipun karya Geertz diakui sebagai karya besar namun taksonomi semacam itu dianggap memiliki banyak kekurangan. Al Qurtuby, misalnya, menegaskan bahwa taksonomi semacam itu mencampur-adukkan kategori "struktural" dan "kultural."22 Priyayi itu lebih merujuk kepada kategori struktural, sementara abangan dan santri merupakan orientasi kultural atau keagamaan. Jadi, tepat sekali jika kita melihat Islam Jawa terutama yang termanifestasikan melalui dua kelompok keagamaan: santri dan abangan. Kelompok kedualah yang akan menjadi sorotan dalam makalah ini.

\section{PANDANGAN DUNIA ISLAM ABANGAN JAWA}

Sekalipun Islam pertama-tama dibawa oleh para pedagang dari India, namun proses "Islamisasi" di Jawa berhasil dengan baik di tangan para Sufi (Mistik). Mengapa demikian? Jawabannya terletak pada sifat dari Sufisme dan agama Jawa itu sendiri. Sufisme, atau Islam mistik, pada dasarnya mementingkan aspek "isi" ("batin" atau mistik) daripada "wadah" (kesalehan normatif yang berpusat pada syariah).23 "Isi" di sini menyangkut: "Allah, sultan, batin dan mistik"; sementara "isi mistik" itu sendiri adalah "wahyu, kasekten, kramat dan kesatuan mistik."24 Selain itu, Sufisme juga dari awalnya sudah bersifat sinkretistik dan sangat akomodatif.25 Demikianlah, Islam mistik-kompromis yang ditawarkan para Sufi itu bertemu dengan kejawen yang juga "condong kepada sinkretisme dan sanggup menampung berbagai ungkapan religius (agama formal) ...."26 Ketika keduanya bertemu, terjadilah bentuk baru sinkretisme yang unik. Koentjaraningrat menggambarkannya sebagai “Agama Jawi” yang selain percaya kepada

20 Woodward, 3.

21 Geertz, 6. Bdk. Woodward, 2.

$22 \mathrm{Al}$ Qurtuby, 66. Woordward juga menegaskan hal yang sama dengan mengatakan bahwa varian priyayi lebih merujuk kepada "kelas sosial" daripada "sektarian" (seperti varian santri dan abangan). Lihat Woodward, 2. 23 Murthado, 22.

24 Ibid, 38; ; lihat juga Woodward, 104.

25 Murthado, 38; Parshall, Bridges, 72; J. Dudley Woodberry, "The Relevance of Power Ministries for Folk Muslims," dalam Great Frontier, 249.

26 Murthado, 12. 
Allah, Muhammad sebagai nabi, nabi-nabi lain, tokoh-tokoh keramat, konsep kosmogoni tertentu dan eskatologi, juga percaya kepada adanya roh-roh halus penjelmaan roh orang yang telah mati, adanya hantu, serta kekuatan-kekuatan gaib di dalam alam.27 Bentuk baru sinkretisme ini utamanya menonjol di kalangan kaum Islam Abangan Jawa, sementara Islam yang lebih murni dipelihara oleh kaum santri.

Rick Love28 memberikan perbandingan antara Islam formal (dianut para Santri) dengan Islam Abangan, sebagai berikut:

\begin{tabular}{|c|c|}
\hline ISLAM FORMAL & ISLAM ABANGAN \\
\hline $\begin{array}{ll}- & \text { Kognitif, berorientasi pada kebenaran } \\
\text { - } & \text { Legalistis } \\
\text { - } & \text { Isu-isu penting dalam hidup: Asal-usul, } \\
& \text { surga, neraka, tujuan hidup } \\
\text { - } & \text { Quran } \\
\text { - } & \text { Tradisi suci } \\
\text { - } & \text { Institusional } \\
- & \text { Suplikatif (permohonan) }\end{array}$ & $\begin{array}{ll}\text { - } & \text { Perasaam hati, Emosional } \\
\text { - } & \text { Mistis } \\
\text { - } & \text { Kepedulian setiap hari: kesehatan, } \\
& \text { petunjuk, sukses, kemakmuran } \\
\text { - } & \text { Kuasa adikodrati } \\
\text { - } & \text { Penyataan rohani } \\
\text { - } & \text { Inspirasional } \\
\text { - } & \text { Manipulatif }\end{array}$ \\
\hline
\end{tabular}

Setiap butir dalam perbandingan dalam tabel ini bisa diisolir dan dijelaskan lebih jauh, namun "kuasa adikodrati" dalam kepercayaan Islam Abangan perlu mendapat perhatian karena ini merupakan pusat dari pandangan dunia mereka.29 Orang-orang Islam Abangan Jawa, seperti halnya dengan orang animis pada umumnya, percaya bahwa kehidupan mereka dikelilingi dan dipengaruhi oleh keberadaan yang berkuasa (berpribadi) dan kekuatankekuatan tertentu (tak berpribadi). Secara konseptual itu dapat digambarkan sebagai berikut:30

27 Seperti yang dikutip Murthado, 35.

28 Diangkat dan diterjemahkan dari Love, 22.

29 J. Dudley Woodberry, "The Relevance of Power Ministries for Folk Muslims," dalam Great Frontier, 249. Gailyn Van Rheenen menambahkan bahwa sebenarnya esensi dari animisme adalah kuasa. Jika ini kita tempatkan dalam kerangka Islam Abang Jawa, maka sangat masuk akal jika pandangan dunia mereka juga berpusat pada kuasa sebab bagi mereka Islam adalah sesuatu yang sekunder. Lihat Gailyn Van Rheenen, Communicating Christ in Animistic Contexts (Pasadena: William Carey, 1991) 21; Andrew Beatty, Variasi Agama Jawa: Suatu Pendekatan Antropologi (Jakarta: RajaGrafindo Persada, 1999) 219.

30 Diterjemahkan dan diadaptasi dari Bill Musk, The Unseen Face of Islam: Sharing the Gospel with the Ordinary Muslims at Street Level (Grand Rapids: Monarch Books, 2003) 160, 162. 


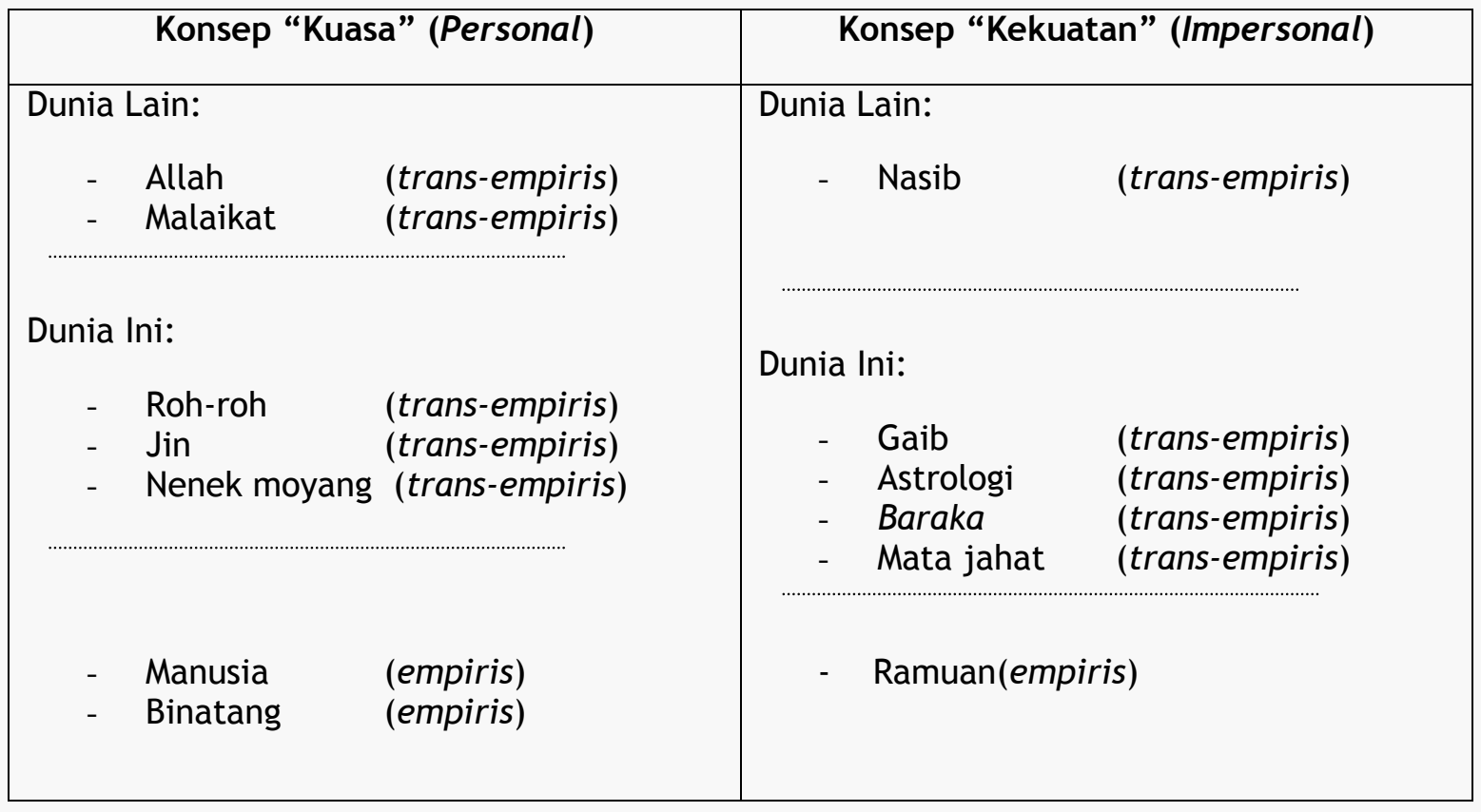

Kehidupan orang-orang Islam Abangan Jawa berotasi di seputar poros dunia trans-empiris. Semua peristiwa yang terjadi dalam kehidupan mereka, misalnya penyakit, tragedi atau berkat, dipahami dalam kaitan dengan dunia trans-empiris sebagai penyebab. Karena dunia trans-empiris bisa bersifat baik dan jahat, kecuali Allah yang selalu baik, orang-orang Islam Abangan Jawa senantiasa berusaha memanipulasi, khususnya yang jahat, demi mencapai tujuan-tujuan mereka. Terlepas dari semua itu, mereka benar-benar hidup dalam ketakutan terhadap dunia trans-empiris. Di sinilah slametan memainkan perannya. Bagi orang-orang Islam Abangan Jawa, slametan tidak hanya memiliki muatan sosio-psikologis, namun juga spiritual. Geertz menegaskan dengan melakukan slametan seseorang terlepas dari beban sosio-psikologis, sebab ia telah melakukan apa yang orang lain lakukan. Namun lebih dari itu, slametan juga merupakan usaha untuk melindungi diri dari gangguan-gangguan dari roh-roh yang dapat membahayakan diri seseorang. 31

31 Geertz, 14-15. Roh-roh dianggap seringkali mencelakai manusia. 


\section{SEBUAH PROPOSAL PENDEKATAN KONTEKSTUAL TERHADAP KAUM ISLAM ABANGAN JAWA}

Menurut Love,32 usaha kontekstualisasi itu dapat dibagi ke dalam lima langkah:

1. Analisa kultural (praktik dan kepercayaan lama).

2. Penelitian ayat-ayat yang relevan.

3. Evaluasi praktik budaya berdasarkan terang Alkitab.

4. Eksperimentasi secara kreatif.

5. Perumusan atau pembakuan bentuk-bentuk baru.

Pada bagian ini, kita akan berusaha merumuskan berdasarkan langkahlangkah di atas, paling tidak no. 1-3 sebab no. 4-5 dibutuhkan partisipasi dan penelitian lapangan, sebuah pendekatan kontekstual terhadap kaum Muslim Abangan Jawa.

Pertama, berdasarkan analisa kultural terhadap pandangan dunia Islam Abangan Jawa di atas, maka sangat jelas bahwa felt-need dari kelompok masyarakat ini bersangkut-paut dengan kuasa. Mereka takut dan sekaligus haus akan kuasa. Paul Hiebert menyebut hal ini sebagai "bidang tengah" yang seringkali diabaikan dan belum digarap dengan benar oleh orang-orang Injili.33 Bahkan salah satu penyebab kegagalan misi Barat di dunia Islam Abangan adalah karena para misionaris, dengan pola pikir dan pelatihan Barat, mengabaikan dimensi spiritual yang sesungguhnya merupakan inti dari pandangan dunia Islam Abangan.34

32 Love, 57-65.

33 Seperti yang dikutip Love, 70. "Bidang atas" meliputi wilayah agamawi dan rohani (dunia transenden: surga, neraka, ilah-ilah, kekuatan kosmis, karma, Yahweh, malaikat, roh-roh jahat); "bidang tengah” berbicara tentang kekuatan adikodrati di bumi (roh-roh, roh-roh nenek moyang, roh-roh jahat, dewa-dewi, sihir, gaib, dsb); akhirnya, "bidang bawah" mencakup gejala-gejala fisik, dan juga psiko-sosial. Lihat juga hlm. 72-73. 34 Vivienne Stacey, yang telah hidup dan melayani hampir seumur hidupnya di tengah-tengah komunitas Islam, menegaskan bahwa orang-orang Kristen seringkali mengabaikan dimensi-dimensi rohani padahal "In reality we are contending with the powers of darkness and not just with people or concepts" di kutip oleh Stuart Robinson, dalam Mosques and Miracles: Revealing Islam and God's Grace (Brisbane: CityHarvest Publications, 2003) 230 . 
Dengan kesadaran akan pengabaian "bidang tengah" tersebut, maka para misiolog kemudian mulai mengembangkan pendekatan misiologis yang disebut dengan "power encounter." Masalahnya adalah bahwa ketika sesuatu yang sebelumnya diabaikan kemudian disadari maka itu lalu mendapat perhatian yang berlebihan.35 Sehingga sekalipun itu harus mendapat perhatian, tetap saja diperlukan kerangka yang dapat mengontrol pendekatan tersebut. Kerangka teologis apa yang dapat memenuhi feltneed di atas dan sekaligus dapat menjadi kerangka? Jawabnya adalah teologi Kerajaan Allah.

Tema Kerajaan Allah itu dinyatakan Allah secara progresif dalam Alkitab. Tema Allah sebagai Tuhan yang memerintah itu nyata di sepanjang PL. Allah disebut sebagai "Raja" dan Israel sebagai "kerajaan imam dan bangsa yang kudus" (U1. 7:6-8; Kel. 19:5-6). Ketika raja-raja dipilih, maka mereka dipilih, diurapi dan sekaligus tunduk di bawah pemerintahan Allah (lih. 1 Sam 10:1). Allah memerintah umat-Nya melalui mereka. Selain itu, PL juga menegaskan Allah bukan hanya Raja atas Israel namun Ia memerintah atas semua. Mz. 103:19 berkata, "TUHAN sudah menegakkan takhta-Nya di sorga dan kerajaan-Nya berkuasa atas segala sesuatu.” Pemerintahan Allah yang universal ini kemudian dinyatakan melalui kedatangan Mesias yang telah dinubuatkan dalam PL (Yes. 52:7; Yeh. 37:24; 34:23).

Seperti yang telah dinubuatkan dalam PL, maka PB selalu melihat tema Kerajaan Allah dalam kaitan dengan pribadi dan karya Yesus-Sang Mesias. Ada banyak aspek mengenai tema Kerajaan Allah dalam PB, namun untuk maksud makalah ini kita akan melihat aspek-aspek yang berhubungan dengan kuasa. Dalam hal ini, Love adalah benar ketika ia menegaskan bahwa banyak kaum Injili yang hanya menekankan aspek relasional (hubungan dengan Allah, pengampunan dan persekutuan) dari kerajaan Allah dan mengabaikan sisi "rescue (or Satanward)."36 Ia melanjutkan bahwa Yesus datang bukan hanya supaya hubungan kita dengan Allah

35 Seperti misalnya doa peperangan rohani "tingkat strategis" yang dikembangkan oleh Peter Wagner. Biasanya diawali dengan pemetaan rohani dan diikuti dengan peperangan melawan roh-roh teritorial. Lihat Peter Wagner, Doa Peperangan: Strategi untuk Bertempur Melawan Penguasa Kegelapan (Jakarta: Metanoia, 1994). 36 Love, 16. 
dapat dipulihkan namun juga menghancurkan pekerjaan Iblis (1 Yoh. 3:8). Melalui pribadi dan karya Kristus kita dilepaskan dari kerajaan kegelapan dan dipindahkan ke dalam kerajaan Allah di bumi ini (Mat. 12:28; Kis. 10:38; Ef. 1:20-21; Kol. 1:12-14; 2:15; Ibr. 2:14; 1 Ptr. 3:21-22).37

Kebenaran di atas inilah yang harus pertama-tama kita tawarkan kepada kaum Muslim Abangan Jawa. Pandangan dunia lama mereka membuat mereka hidup dalam ketakutan akan kuasa-kuasa. Sekalipun ada yang dapat mereka manipulasi namun banyak juga yang berada di luar kendali mereka. Dengan gaya hidup semacam itu mereka telah tertipu dan dibutakan oleh Iblis. Sehingga dalam fase pertama, mereka harus bertemu dengan kebenaran ini (truth encounter): Kristus datang untuk melepaskan mereka dari kuasa kegelapan! Selanjutnya mereka, yang sudah sangat terbiasa dengan pertunjukan kuasa, harus melihat dengan mata kepala mereka sendiri demonstrasi kuasa Allah (power encounter). Baru kemudian mereka dapat dipimpin ke dalam komitmen yang lebih dalam kepada Kristus (commitment encounter).38 Hanya dengan demikian, para petobat Muslim Abangan Jawa bukan hanya tahu tetapi juga mengalami kuasa kelepasan dari Kristus, dan bukan hanya mengalami tetapi juga menjadi pengikut Kristus yang sejati.

\section{KESIMPULAN}

"Ngelmu” (mencari kesaktian), "jimat," “tapa” (bertapa), “jin,” "tuyul," "mantera," "sesajen," adalah hal-hal yang sangat akrab dalam kehidupan orang-orang Islam Abangan Jawa. Secara historis, Islam Abangan Jawa terbentuk oleh perpaduan antara Islam dan kepercayaan-kepercayaan lokal yang animistik. Sekalipun banyak yang keberatan untuk melihat

\footnotetext{
37 Ibid.

38 Charles H. Kraft membagi perjumpaan antara manusia dengan Tuhan ke dalam 3 perjumpaan, yaitu: kebenaran (truth); kuasa (power) dan komitmen (commitment). Kraft "What Kind of Encounters Do We Need in Our Christian Witness?” dalam The Last Great Frontier, 237-245. Sementara Love menambahkan dua lagi, yaitu: perjumpaan moral dan budaya. Sebenarnya kedua perjumpaan ini bisa dikategorikan sebagai sub-ordinat dari perjumpaan komitmen, di mana petobat Muslim kemudian dimuridkan sehingga ia mengadopsi etika Kerajaan Allah serta mengekspresikan realitas kerajaan Allah melalui ritual-ritual yang telah dikontekstualisasikan.
} 
perpaduan ini dari kacamata modern (menang-kalah), namun kenyataannya unsur lokal mengungguli keislaman. Demikian Geertz menegaskan, “... abangans are fairly indifferent to doctrine but fascinated with ritual detail ..."39 Untuk itu, usaha kontekstualisasi seharusnya tidak diarahkan kepada unsur-unsur Islam, namun kepada pandangan dunia animistik Islam Abangan Jawa yang berpusat pada kuasa.

Teologi kerajaan Allah adalah konsep yang sangat tepat untuk menjawab kebutuhan tersebut. George E. Ladd menegaskan bahwa Yesus melanjutkan gagasan PL bahwa kedatangan kerajaan Allah itu diwujudkan melalui penaklukkan musuh. Namun di sini Yesus tidak memahaminya dalam pengertian militer, tetapi spiritual. Kedatangan Yesus yang pertama menaklukkan "penguasa dunia ini"-Iblis, dan selanjutnya itu akan digenapi secara penuh pada saat kedatangan-Nya yang kedua kali. Ladd menulis, "The coming of the Kingdom as an eschatological event will mean nothing less than the destruction of the Devil and his angels in eternal fire (Matt. 25:41) at Parousia of the Son of Man."40 Inilah berita yang paling dibutuhan oleh kaum Muslim Abangan Jawa: Kristus sebagai Pelepas! Selain itu, teologi kerajaan Allah, dalam konteks peperangan antara dua kerajaan, dapat memagari usaha kontekstualisasi terhadap bahaya sinkretisme. Dalam konteks Islam Abangan Jawa, sinkretisme adalah bahaya yang sangat riil. Pandangan dunia mereka sangat sinkretistik sehingga amatlah mudah bagi mereka untuk mengintegrasikan kepercayaan baru dengan kepercayaan lama mereka. Namun teologi kerajaan Allah, dalam pengertian dominasi, berarti peralihan kekuasaan. Bukan hanya dalam hal kepercayaan namun semua segi kehidupan harus ditundukkan di bawah pemerintahan Allah. Dengan demikian, Teologi Kerajaan Allah memungkinkan proses kontekstualisasi berjalan sampai tuntas.

39 Geertz, 127. Beatty juga menegaskan, 'Orang-orang Jawa secara sederhana dapat didefinisikan sebagai orang-orang yang cenderung menekankan bagian Jawa dari warisan kultural mereka dan menganggap afiliasi Muslim mereka sebagai hal sekunder' (penekanan ditambahkan). Lihat Beatty, 219.

40 George Eldon Ladd, The Presence of the Future: The Eschatology of Biblical Realism (Grand Rapids: Eerdmans, 1974) 150-151. 


\section{DAFTAR KEPUSTAKAAN}

Al Qurtuby, Sumanto. "Sinkretisme dalam 'Islam Jawa." WASKITA: Jurnal Studi Agama dan Masyarakat Vol. I, no. 1 (April 2004) 63-80

Azra, Azyumardi. Islam Nusantara: Jaringan Global dan Lokal. Bandung: Mizan, 2002.

Beatty, Andrew. Variasi Agama Jawa: Suatu Pendekatan Antropologi. Jakarta: RajaGrafindo Persada, 1999.

Bevans, Stephen B. Models of Contextual Theology. New York: Orbis Books, 1999.

Geertz, Clifford. The Religion of Java. Illinois: The Free Press, 1960.

Ladd, George Eldon. The Presence of the Future: The Eschatology of Biblical Realism. Grand Rapids: Eerdmans, 1974.

Love, Rick. Muslims, Magic and the Kingdom of God. Pasadena: William Carey, 2000.

Murthado, M. Islam Jawa: Keluar dari Santri Vs Abangan. Yogyakarta: Lappera Pustaka Utama, 2002.

Musk, Bill. The Unseen Face of Islam: Sharing the Gospel with the Ordinary Muslims at Street Level Grand Rapids: Monarch Books, 2003.

Parshall, Phil ed. The Last Great Frontier: Essays on Muslim Evangelism. Quezon City: Open Doors with Brother Andrew, 2000.

- Bridges to Islam: A Christian Perspective on Folk Islam. Grand Rapids: Baker, 1983

Robinson, Stuart. Mosques and Miracles: Revealing Islam and God's Grace. Brisbane: CityHarvest Publications, 2003.

Van Rheenen, Gailyn. Communicating Christ in Animistic Contexts. Pasadena: William Carey, 1991.

Wagner, Peter C. Doa Peperangan: Strategi untuk Bertempur Melawan Penguasa Kegelapan. Jakarta: Metanoia, 1994. 
Woodward, Mark R. Islam Jawa: Kesalehan Normatif Versus Kebatinan. Yogyakarta: LKiS, 1999. 